\title{
University Centers Programs: Creative Solutions For Serving Remote Populations
}

Vincent J. Vicari, (E-mail: VicariV@wpunj.edu), William Paterson University Stephen C. Betts, (E-mail: BettsS@wpunj.edu), William Paterson University

\begin{abstract}
University Centers programs are designed to provide University level classes to students at remote locations and to facilitate a transition from local two-year institutions to regional four-year institutions. Although similar in concept to satellite campuses and often using technologies associated with distance learning, University Centers programs also have unique characteristics that bring additional issues and concerns that need to be addressed. In this paper we introduce the University Centers concept and review related administrative arrangements and uses of technology. We then explore the unique issues and concerns of University Centers, drawing upon the experiences of one university's involvement with University Centers for examples of both opportunities and solutions. Guidelines will be presented for universities that are considering becoming involved in a University Centers program.
\end{abstract}

\section{INTRODUCTION}

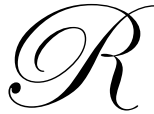

emote course delivery is an idea that has been around for hundreds of years, however advances in technology and changes in societal attitudes towards learning has made it a very current and vibrant area in higher education. One innovative approach is the university center, which not only serves remote populations but also bridges the gap between two year and four year institutions. University centers programs focus on the objectives of providing baccalaureate courses through the county college system, and are not dependent on a single technology or technique. As such, they employ a variety of traditional and cutting edge course delivery methods and administrative arrangements to achieve their goals. This paper presents the university centers concept, explores some of the unique challenges associated with such programs. In exploring these issues, the paper draws on the experiences of a successful university centers programs and shows how the challenges were met.

The paper begins with a description of university centers programs. Other alternatives to the traditional fixed campus classroom are explored next. This is followed by a discussion of how technology has enabled such approaches. Four categories of issues unique to university centers are addressed next - advising and counseling, faculty deployment, access to resources and facilities management. After the general issues are presented, illustrations of specific problems encountered and how they were addressed by one program are presented. The specific program is the University Centers at William Paterson University, where one author is the university centers director and other is a professor that taught in the program. The paper concludes with a table that summarizes some of the typical problems associated with university centers and potential solutions.

\section{UNIVERSITY CENTERS AND REMOTE LEARNING}

\section{University Centers Concept}

University centers provide baccalaureate courses in areas with limited access to four-year institutions through the Community College system. A generation ago community colleges provided two year degrees and training to students that were not eligible or capable of pursuing a four year degree. In recent times the community college has 
emerged as less of an alternative and more of a feeder institution where students begin their education before moving to a four year institution to complete a degree. By providing university level classes to students at remote locations, university centers programs serve to facilitate a transition from local two-year institutions to regional four-year institutions.

\section{Alternative Learning Models}

There are various methods of course delivery that are available besides the traditional fixed campus classroom. There are records of correspondence study by mail as far back as 1728 , and by the end of the nineteenth century it was a popular method for place bound learners to complete a course of study (Bowers \& Hardy, 2004). For example, the Boston-based Society to Encourage Study at Home provided over twenty course that housebound women could complete at home (Simonson, Smaldino, Albright \& Zvacek, 2000). Another early option that still persists is holding courses at remote locations or 'satellite campuses'. These are used throughout the world in places like Australia (Rindeleish, 2003), Nigeria (Fatunde, 2001) and the Scottish Highlands (Carter, 1994). These satellites serve remote populations that have enough students to justify a few classes, such as the University of Queensland which set up a campus specifically to serve rural women who cannot travel to a traditional institution (McCann, 1994). Besides place bound students, options are available for serving working adults and professionals requiring time efficient models to balance both professional and domestic responsibilities. One institution, National University in San Diego had its birth serving the educational needs of working adults in an accelerated one month-per-class format. Opening new locations following the sprawl of population movement in California and opening up "campuses" in strip malls and renting floors of office buildings where businesses were in need of localized education.

\section{Technology Enabled Learning}

Although correspondence, satellite campuses and accelerated programs each have advantages, they cannot provide the rich collaborative learning, sense of community and engagement available at a traditional campus. Recent technological advances have created new options for engagement (Laird \& Kuh, 2005). For example online formats can use discussion boards to build a learning community (Wilson, Cordry \& King, 2004) and online formats can used to facilitate debates as a teaching tool (Kam, Carrie \& Thomas, 2004). Interactive television (ITV) can serve multiple locations simultaneously. ITV was once rare and expensive, but now is within the reach of most institutions, with various technological options varying in capacity, reliability and cost. The next generation will be mixed or 'hybrid' delivery (Swisher \& Whitfield, 2005), with some considering hybrid courses "one of the first real shifts in teaching and learning practice since the first printing press was invented' (Lorenzetti, 2004).

University Centers classes, aided by the general maturity of adult learners, can be structured as a yet to be definitively defined "hybrid" class where official contact hours are split between arranged in person and scheduled online formats. Progressive courseware, Blackboard ${ }^{\mathrm{TM}}$ is utilized to serve both synchronous and asynchronous remote learning. Although at the beginning stages of the experience curve, students and faculty need not be in the same airspace to adequately share a rich learning environment. Currently, online components make up the bulk of the distance components with Interactive Television only sparsely implemented. However, with IP protocol now cheaply and widely available, implementation of teleconferencing as a teaching modality is clearly focused on the horizon. With streaming video over IP products, remote students can "drop-in" to live classes when the weather or business travel interferes with commuting to a classroom.

\section{ISSUES UNIQUE TO UNIVERSITY CENTERS}

\section{Advisement and Counseling}

Proper advisement and counseling are critical to the success of any student and thus the long-term success of many programs. The value of specific courses in how they fit into the academic sequence and the greater program must be communicated to current and potential students. In a remote program, being detached from the infrastructure of main campus, students may lack fast and easy access to such advisement. The University Centers is no exception to this possibility as Dept. Chairs, academic advisors, and the Universities general advisement center would be a far 
reach from the Community College facilities. Furthermore, programs that frequently change, such as education, could leave students in the dark when it comes to proper course choices and those for compliance with State or County requirements for licensure or certification.

\section{Faculty Deployment}

Faculty tends to have rigorous research, teaching, committee, and community involvement tasks that strain personal and work schedules. Accreditation requirements provide guidelines for full time to adjunct ratios, which must conform to main campus profiles. So, the need to utilize regular full time, tenure track, main campus faculty is a real charge as well as the need to develop a complimentary remote faculty arsenal which can "fill-in" rather than assume the full teaching burden.

\section{Access to Resources}

Many accreditation bodies raise a critical eye to off campus programs measuring them against a litmus test of "equal access to human, academic, and technical resources. Easy access to senior faculty, library materials including those that may not be web products, and specific technical resources must be facilitated at remote sites. The creation of a full course offering must have such resources available to remote populations for the extension campus to be in accreditation compliance. Beyond accreditation concerns, reduced access to resources might force instructors to downplay such things as library research, and in the process shortchange the students (Shorr, 2004).

\section{Facilities Management}

Control of academic offerings takes place not only in the structured classroom. It also takes place in the "control" that exists over a remote site. Having classes in a facility, not unlike subcontracting out a factor of production, increases the instance of events upsetting class flow as a parallel offering to main campus. Faculties are acclimated to main campus schedules. Community Colleges, on the other hand are operating on a slightly different calendar. Not only faculty, but also students taking courses at multiple locations may find conflicting holiday, weather closing, and differing academic schedules between main campus and the remote site.

\section{THE UNIVERSITY CENTERS OF WILLIAM PATERSON UNIVERSITY}

The University Centers at WPU had been created in for a number of social and institutional reasons. Born in compliance to a 1997 Transfer Articulation Principles for New Jersey Colleges and Universities, embarked upon by participating Community College and NJ State University Presidents was to provide NJ remote populations with an opportunity to earn University level programs in their community. "The ability to transfer credits from one institution to others is a matter of particular importance to students and the State because it saves both money and time by eliminating unnecessary duplication and repetition of courses." Thus transfer credit migration and the "ideal" objective of a seamless transfer to senior institutions was an original goal and charge of the participating institutions.

WPU took the lead in the Northwest areas of NJ by creating an extension of its main campus within the Sussex, Morris, and Warren county community college infrastructure. The WPU University Centers has company within its target market. Fairleigh Dickinson University, Centenary College, Jersey City State all have course and program offerings with varying degrees of success. All slow growth programs with the costs associated with assigning live faculty to situations where enrollment levels not considered adequate for "normal" courses to run.

As the Sussex, Morris, and Warren communities are well served through the respective county colleges, those facilities are the likely places to host these partnership programs. Thus, embedded within the campuses of three community colleges, WPU was charged by a "public policy" to remotely offer three initial programs on the county college properties. Beginning with Business Management, Sociology - Criminal Justice and beginning courses in education were embarked upon as a pilot. These were to evolve to full-fledged program offerings where students could complete their baccalaureate degrees within 18 months. This feature, although not a public policy charge had been a selling point for the original cohort of students. 
Other charges in relation to transfer issues, in addition to logistical deployment, were a major undertaking of the University Centers concept. "The Presidents' Council should strive for a seamless transition from associate to baccalaureate degree programs. Some transfer students were to be viewed as "transparent and afforded preferential transfer treatment in the acceptance of transfer credit and class standing at the senior institution. A liberal transfer credit policy, acceptance of general education requirements, program admissions, an articulation agreement, Institutional Coordination, and Statewide Curriculum Coordination are all aspects of the University Centers Initiative approved by an Executive Committee, New Jersey Council of Presidents: May 19, 1997

\section{ISSUES, OPPORTUNITIES AND SOLUTIONS AT THE UNIVERSITY CENTERS OF WILLIAM PATERSON UNIVERSITY}

\section{Advisement and Counseling}

Advisement and counseling are mentioned earlier as a requirement of remote campuses. In parallel, these structures already exist at the Community College facilities which can, if embraced, be a catalyst for enrollment growth at senior institutions. In the University Centers program a strong in person networking relationship has been build upon personal foundations and a constant presence at these sites. Attendance at Community College events, such as dedications, graduations, local community events, and issues important to the faculty and staff of the partner community colleges and community facilities is imperative to an integrated relationship. This arrangement will utilize the informal channels to funnel student leads and market opportunities which otherwise would not be a formal channel of transfer referral. A strategic mix of rapport building and business building relationship management is relied upon extensively. The University Centers has been able to keep recruitment costs down and completely variable by relying upon the community college counselors to refer, maintain, and assist in urgent remote student needs.

\section{Faculty Deployment}

One major area for development is a structured deployment process for faculty and staff to work at the centers. The prospect of travel to remote teaching facilities is not as popular as teaching down the hall from a professors last class on main campus. The University Centers locations encompass a 137-mile radius from main campus in Wayne, NJ. Travel on weekends to NJ western campgrounds and recreational facilities are a fun summertime excursion. However, during rush hour traffic, obstacles offered by frequent construction, road detours, and normal highway obstructions make travel less than ideal on a daily basis. If the proportion of full time/part time faculty utilization is to be correctly profiled, then incentives must be offered to attract tenure line faculty to support the programs off-site. The University Centers structure does not, other than travel, offer excess remuneration for teaching distance learning courses. One approach is to allow faculty the freedom to experiment, utilize new technology, and employ innovative pedagogy when serving the remote population.

\section{Access to Resources}

At WPU we are the proud host of the E*Trade Center, the Russ Berrie sales lab, and other technical teaching resources which are not available in full remotely. The WPU College of Ed has educational technology licensed in lab settings also not available at remote locations. Remote programs are required to provide equal access to human, technological, and academic resources to its off site students. Academic Advisors, Departmental Faculty, Department Chairpersons, Associate Deans, Deans, and University Staff continue to operate at a distance to student populations. With the exception of the Director of the University Centers, and teaching faculty on the front line, students could be at a loss for vital services. One answer to this challenge is the deployment of a teleconferencing system linking the two institutions and the remote students. A low cost, always on connection is the ideal link, which should be answered by the senior institution with a routing capability for instant answers and connection to specialties not readily available at the remote sites. This is done via a static IP address over NJEDge, a dedicated broadband network created to carry ITV courses but not used for advisement purposes to date.

Course delivery via ITV is a little known secret across University Campuses. Seemingly an easy solution to remote course offerings, it does not offer the creature comforts of 3D interaction. All but a handful of faculty feels comfortable with this medium, and students are not filling the registration lines to get into these courses. Many 
parallel issues are at hand here, but clearly we are at the beginning of a long learning curve to widespread adoption across the curriculum and program offerings. With only a select few course being so offered, we are making incremental steps toward widespread acceptance. One author of this paper has actively taken on the challenges of delivering content and interaction rich courses via ITV while at the same time overcoming the institutional impediments that have stunted the growth of this medium of delivery. Flexibility in the classroom and contingency planning along with a sense of humor are the basic ways of dealing with the technical challenges while creating and maintaining a sense of community.

Lastly, for a full educational experience, the students need access to academic resources. The primary solution is to provide remote access to academic resources. Certainly, Community colleges have adequate libraries and research materials. The issue remains in that copyrighted material and licensed software are owned by the community colleges and may exclude non-native students from utilizing these resources. Lacking a dual enrollment status, with courses being mismatched in topics and class levels, the community college partners are not in a position to issue the student Id's that would allow for network access. Thus, easy PC access for email, either CC or senior library access, courseware such as blackboard, and non web access databases would be inaccessible to University Centers students. An answer to this, and within the short term goals of the University Centers, is a fixed installation over broadband connection of a Video over IP teleconferencing system, Wifi student access link, and a fixed space to serve as a remote operations command center. This is currently being built at one of the Three University centers and with forward plans to mutate this model to the other four locations.

\section{Facilities Management}

The maintenance of a remote should have as its goal "control" to support a first class academic quality and consistency to main campus schedules. Quality of academic offerings is the responsibility of the director of such a program as that person would be the catalyst to balance conflicting site priorities. For instance, in one such scenario a remote site had an unrelated graduation for approx 600 firemen's class, and swarming upon the site were all the family and friends of the graduates. The academic offerings happening on that day must be "policed" as not to have numerous interruptions of the classroom environment. This one example should be understood in the context that whatever can go wrong, will go wrong when the shift in management of the site moves from simply space, to the reality that academics must be protected at all costs. On demand reaction to unforeseen events is a must despite little or no remote assistance. Challenges arise when multiple sites have classes in parallel and travel between limits the ability to react instantly to multiple site anomalies. One solution, although not sensitive to faculty availability issues, is to alternate classes as not to duplicate days and times at off site locations. This model, although attempted, is not always a viable alternative given scheduling issues.

Table 1 - Selected Examples of Typical Problems and Potential Solutions

\begin{tabular}{|c|c|}
\hline Typical Problems & Potential Solutions \\
\hline \multicolumn{2}{|c|}{ Advising and Counseling } \\
\hline Student access to advisor & ITV, dedicated UC advisor \\
\hline Curriculum requirements & posted on website, contact person \\
\hline Career guidance & local CC advisors \\
\hline Faculty Deployment & reimbursement, ITV/online options \\
\hline Travel & multi-campus ITV/online, rotate offerings \\
\hline Enrollment & multi-campus ITV/online, rotate professors \\
\hline Full/Part time ratios Access to Resources \\
\hline \multicolumn{2}{|c|}{ online access, reciprocating agreements } \\
\hline Library & online access, reciprocating agreements \\
\hline Administrative departments & proxy arrangements \\
\hline Room assignment & dedicated advocate, contingency plan \\
\hline Room management & contact person, contingency plan \\
\hline Technology & remote deployment, flexible pedagogy \\
\hline
\end{tabular}




\section{CONCLUSIONS}

In this paper we have introduced the university centers concept. We placed it in the context of traditional university education and compared and contrasted it to current and historical methods of reaching remote populations. Some of the unique challenges that arise in enacting a university centers program were sketched out and some of the potential solutions were offered. This general discussion was illustrated with specific examples from the authors' first hand experiences with the University Centers of William Paterson University. Some of the typical problems and potential solutions discussed in the text are summarized in Table 1. The university centers approach to serving remote populations and connecting local two-year colleges to regional four-year universities is relatively new, but it the value to students and schools is already evident. As the challenges are met and overcome, processes and procedures refined and new pedagogical techniques developed, the university centers approach will become a valuable tool in meeting tomorrow's higher education challenges.

\section{REFERENCES}

1. Bower, B.L. \& Hardy, K.P. 2004. From correspondence to cyberspace: Changes and challenges in distance education. New Directions for Community Colleges, 128: 5-14

2. Carter, I. 1994. Remote learning is getting closer. Times Educational Supplement, 4084: 33

3. Fatunde, T. 2001. End of line for the satellite campus. Times Higher Education Supplement, 1504: 10

4. Jugdev, K., Markowski, C. \& Mengel, T. 2004. Using the Debate as a Teaching Tool in the Online Classroom. Online Classroom, Oct 2004: 4-7

5. Lorenzetti, J.P. 2004. For Quality and Cost Effectiveness, Build a Hybrid Program. Distance Education Report, 8(21): 1-3

6. Laird, T. \& Kuh, G. 2005. Student Experiences With Information Technology And Their Relationship To Other Aspects Of Student Engagement. Research in Higher Education, 46(2): 211-233

7. McCann, H. 1994. Creating More Learning Opportunities for Women at University. Bulletin of Good Practice in Popular Education, 1994 (2): 14-17

8. Rindfleish, J.M. 2003. Segment profiling: reducing strategic risk in higher education management. Journal of Higher Education Policy \& Management, 25(2): 147-159

9. Sachs, S.G. 2004. Institutional issues when distance learning joins the mainstream. New Directions for Community Colleges, 128: 23-31

10. Shorr, C. 2004. Interlibrary Cooperation and Resource Sharing to Better Serve Distributed Learners. College \& Research Libraries News, 65(8): 432-433

11. Simonson, M., Smaldino, S., Albright, M. \& Zvacek, S., 2000. Teaching and Learning at a Distance: Foundations of Distance Education. Upper Saddle River, N.J.: Prentice Hall.

12. Swisher, S. \& Whitfield, C. 2005. Embracing Several Generations In Distance Learning. Corrections Today, February: 80-82.

13. Wilson, J.D., Cordry, S.A. \& King, N. 2004. Building Learning Communities with Distance Learning Instruction. TechTrends: Linking Research \& Practice to Improve Learning, 48(6): 20-22 